\title{
Expression III (I): A Cross Cultural Analysis of Ovarian Cancer Patient's Preferences and Expectations on Physician-Patient Communication and Clinical Management in India and Germany
}

\author{
Kar $\mathbf{S}^{1 \#}$, Alavi $\mathbf{S}^{1,2 \#}$, Oskay-Ozcelik G ${ }^{1,2}$, Keller $\mathbf{M}^{1,2}$, \\ Richter $\mathbf{R}^{1}$ and Sehouli J ${ }^{1,2 *}$ \\ ${ }^{1}$ Charité-Universitätsmedizin Berlin, Corporate Member \\ of Freie Universität Berlin, Humboldt-Universität zu \\ Berlin, and Berlin Institute of Health, Department of \\ Gynecology, European Competence Center for Ovarian \\ Cancer, Germany \\ ${ }^{2}$ North-Eastern German Society of Gynecological \\ Oncology (NOGGO), Berlin, Germany \\ ${ }^{\#}$ Contributed Equally \\ *Corresponding author: J alid Sehouli, Department \\ of Gynecology and Obstetrics, Charité-Campus Virchow- \\ Klinikum University Medicine of Berlin, Augustenburger \\ Platz 1, 13353 Berlin, Germany
}

Received: January 15, 2021; Accepted: February 27, 2021; Published: March 06, 2021

\begin{abstract}
Background: The information level and expectations of the patients suffering from cancers should be taken as a basis for the treatment decisionmaking process. Nevertheless, there are lacking data in both developing and western countries. The objective of this survey was to identify similarities and differences between patients with ovarian cancer from India and Germany in regard to the information needs and expectations concerning physician-patientcommunication and treatment.
\end{abstract}

Patients and Methods: This study was based on the European survey "Expression III". The German subgroup was compared to an Indian cohort. The study was conducted in the state of Odisha, India using an English translation of the same questionnaire with 43 items.

Results: Overall, 86 Indian patients (median age 52y, range 19-76 y) and 427 German patients (median age 62y, range 26-84y) participated in this survey. The most valuable suggestions made by German patients to improve the treatment of ovarian cancer was 'the therapy shouldn't lead to hair loss $(49 \%)$ ', whereas the Indian patients whished for a treatment of shorter duration $(47 \%)$. The majority of German (90\%) and the Indian (79\%) patients consider their treating physician to be most effective and patient-friendly information source. Fear of the future was the most difficult aspect of their illness to handle by both study populations (43\% India / 55\% Germany). Compared to $46 \%$ of German patients, not a single patient in India was involved in a study or clinical trial.

Conclusions: The study underlines the key role of the physician as the most relevant source of information for patients in both countries. In spite of a significant difference in the socio-economic status, the expectations from their physicians found to be similar in many aspects.

Keywords: Ovarian cancer; Physician-patient relationship; Survey; Developing country

\section{Introduction}

While a large number of studies have been conducted to compare the incidence, prevalence and the situation of cancer patients among European countries or the western world [1,2], only few studies address differences among cancer patients from developed and developing countries [3-5].

Ovarian cancer remains to be the fifth leading cause of death from cancer in women worldwide, while population-based cancer registries in India state ovarian cancer to be the fourth leading site of cancer among women $[2,6,7]$. While the reported incidence rate in Germany is 14 per 100,000 women, an increase of the age-adjusted incidence rate, which is between 5.4 and 8.0 per 100,000 depending on the region of the country, has been reported in India in recent years [6-8]. Due to the lack of effective screening tests, the majority of patients are diagnosed at an advanced stage and the prognosis remains poor independent of the stage of economic development of the respective country.

In the present survey we compared patients suffering from ovarian cancer in Germany as an example of a developed country and in India representing a developing country. With the knowledge that intercultural differences can influence the reception of information and patients' needs [9], the aim of this study was to detect possible differing preferences concerning information received about their illness and therapy as well as the physician-patient-relationship.

\section{Methods}

This study was based on the European survey "Expression III" [10]. It is a concept of the working group "Supportive Therapies" of the North-East German Society of Gynecological Oncology (NOGGO) and has been conducted within the European Network
Austin J Obstet Gynecol - Volume 8 Issue 2 - 2021

Submit your Manuscript | www.austinpublishinggroup.com

Sehouli et al. (C) All rights are reserved
Citation: Kar S, Alavi S, Oskay-Ozcelik G, Keller M, Richter R and Sehouli J. Expression III (I): A Cross Cultural Analysis of Ovarian Cancer Patient's Preferences and Expectations on Physician-Patient Communication and Clinical Management in India and Germany. Austin J Obstet Gynecol. 2021; 8(2): 1168. 


\section{for Gynecological Oncological Trial Groups (ENGOT).}

Patients with the diagnosis of primary or relapsed ovarian cancer were invited to take part in the survey. A minimum age of 18 years was defined as a criterion for inclusion.

The German data was collected between January and December 2008 via hard copy version, which was sent to 87 participating academic and non-academic centers and once the forms have been filled, was sent back to the study center.

Simultaneously between February and March 2008 the survey was conducted in India in a government regional cancer center, in a private medical university as well as in two private hospitals. The questionnaire was translated into English, but since most of the patients were not capable of the English language, the interview was conducted in Odia, the regional language spoken in the state of Odisha.

The first part of the questionnaire involving 16 items focused on demographic and therapeutic data. The remaining 27 of overall 43 questions concerned patients' expectations with regard to the physician-patient relationship and information needs. Questions could be answered as multiple choice or as free text. Three questions could be answered on a 10-point scale. The acquired information concerning the course of disease of the Indian study population was additionally verified by hospital records.

\section{Statistics}

$\mathrm{IBM}^{\circ}$ SPSS $^{\circ}$ (Release 10) was used for statistical analyses and data processing. For continuous variables, median and ranges were calculated and Mann-Whitney-U test was used. Chi-Square test was used for categorical variables. For some questions, patients were asked to rate their answers from 1 to 10 in Likert scale. The statistical analysis of the given answers focused primarily on a descriptive analysis. The Kendall's tau b rank correlation coefficient was used to measure the association between the two groups for those answers.

\section{Results}

\section{Patient's characteristics}

Overall, 86 Indian patients with a median age of 52 years (range 19-76 years) and 427 German patients with a median age of 62 years (range 26-84 years) participated in this survey. Fifty-five per cent of German participants were aware of their tumor stage upon diagnosis with 68 patients $16 \%$ (68 patients) initially being diagnosed with FIGO-Stage I/II and 39\% (167 patients) with FIGO-Stage III/IV. In comparison, significantly more Indian patients were at an advanced stage upon diagnoses $(\mathrm{p}<0.001)$ with $12 \%$ (10 patients) being diagnosed with FIGO-Stage II and 59\% (51 patients) with FIGOStage III/IV. Not a single Indian participant was initially diagnosed with FIGO-Stage I, whereas ovarian cancer could be detected in $9 \%$ of the German participant in the earliest stage. Recurrent disease was reported from 175 German (41\%) and 37 Indian (43\%) participants (Figures 1-3).

In Germany, the majority of patients had primary surgery (94\%) followed by first-line chemotherapy (86\%), while 58 (68\%) Indian patients received a surgical treatment and 84 (98\%) were treated with chemotherapy (Table 1).

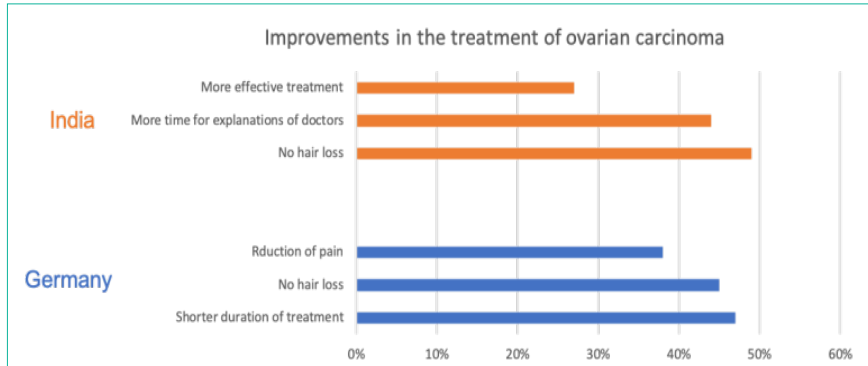

Figure 1: Improvements in the treatment of ovarian cancer.

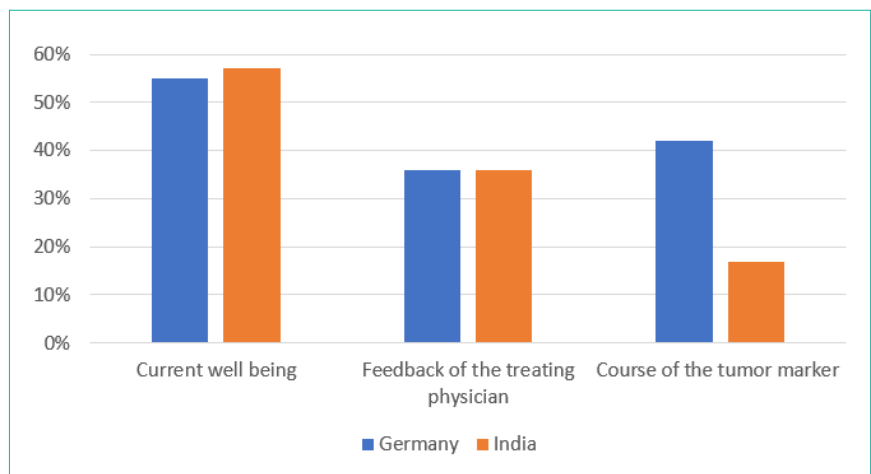

Figure 2: How do you measure the success of therapy?.

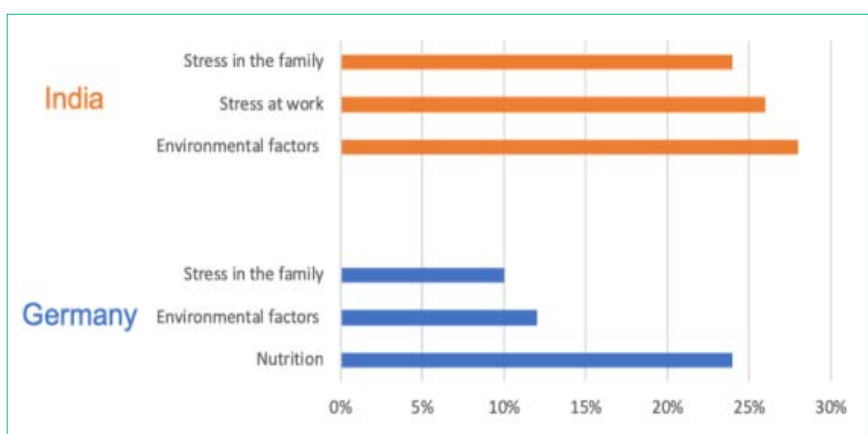

Figure 3: What is the cause of your illness?.

At the time of the study, $46 \%$ of German and $65 \%$ of Indian responders were under current treatment, the majority receiving chemotherapy. With $84 \%$ of the German patients receiving platinum-based chemotherapy, $78 \%$ received carboplatin and $6 \%$ received cisplatin. In contrast, of the $61 \%$ of Indian patients with platinum-based chemotherapy only $12 \%$ received carboplatin and $49 \%$ received cisplatin. The three most common side effects of treatment reported by the German study population were hair loss (81\%), polyneuropathy (65\%) and fatigue-syndrome (58\%), while the Indian study population suffered the most from nausea and vomiting (78\%) followed by hair loss (77\%) and pain (48\%). Compared to $46 \%$ in Germany, not a single patient in India was involved in a study or clinical trial.

\section{Information needs}

The participants were asked to rate the completeness and comprehensibility of the information provided during their last consultation by the treating physician. The majority of both study population gave top scores of eight and higher with no significant 
Table 1: Patient's characteristics.

\begin{tabular}{|c|c|c|}
\hline \multicolumn{1}{|c|}{ No. of Points } & 427 & 86 \\
\hline Median age, years (range) & $62(26-84)$ & $52(19-76)$ \\
\hline Stage of disease & & \\
\hline Primary ovarian cancer & $252(59 \%)$ & $49(57 \%)$ \\
\hline Relapsed ovarian cancer & $175(41 \%)$ & $37(43 \%)$ \\
\hline FIGO Stage III-IV & & $10(12 \%)$ \\
\hline Unknown & $167(16 \%)$ & $51(59 \%)$ \\
\hline Yes & $192(45 \%)$ & $25(29 \%)$ \\
\hline No & $196(46 \%)$ & $56(65 \%)$ \\
\hline Current treatment & $231(54 \%)$ & $30(35 \%)$ \\
\hline Surgery & $401(94 \%)$ & $58(68 \%)$ \\
\hline Chemotherapy & $367(86 \%)$ & $84(98 \%)$ \\
\hline
\end{tabular}

differences. Furthermore, top scores were given by German and Indian responders concerning the competence of their treating physician ( $\geq 8$ Germany $73 \%$; India $86 \%$ ) and their participation in therapy decisions ( $\geq 8$ Germany $57 \%$; India $44 \%$ ). Indian participants ( $\geq 8$ points $95 \%$ ) perceive their relatives to be more involvement in decisions concerning their disease and therapy compared to German participants ( $\geq 8$ points $55 \%$ ). When asked to rate the received responses to questions during consultations Indian patients ( $\geq 8$ points India $86 \%$ ) were significantly more satisfied $(\mathrm{p}<0.018)$ compared to German patients ( $\geq 8$ points Germany $73 \%$ ).

Whether they are getting the right therapy, was the most important information for $47 \%$ of the Indian patients and $69 \%$ of the German patients. The second important information was how long they would live ( $40 \%$ India / 28\% Germany).

\section{Perception of treatment and side effects}

We asked the participants to rate the success of their therapy, the distress caused by side effects, distress associated with surgery, pain, nausea and vomiting as well as the extend of exhaustion. Regarding the success of therapy, the majority of patients experienced it to be better than expected with no significant difference between the two study populations. Similar results were seen regarding the expected side effects of therapy.

Indian patients asked for a shorter duration of treatment (47\%), no hair loss $(45 \%)$ and the reduction of pain (38\%) when asked what should be improved in the treatment of ovarian carcinoma, while German patients asked for no hair loss (49\%), more time for explanations from doctors (44\%) and a more effective treatment (27\%).

The majority Indian and German patients measured the success of therapy based on the current well being (India 57\%; Germany $55 \%$ ) and the feedback of the treating physician (India 36\%; Germany $36 \%)$. However, only $17 \%$ of Indian patients consider the course of the tumor marker as measurement for therapy success, compared to $42 \%$ of German patients.

We asked the patients about the aim of the therapy. Seventy-three per cent of Indian and 59\% of German patients hoped for a complete healing without any further complications and $27 \%$ of the Indian patients hoped for a less painful course of sickness. Further 59\% of German participants hoped for no recurrence of tumour-related symptoms.

\section{Information source}

The majority (81\%) of the Indian patients an $73 \%$ of the German patients said that they received the most support from a 'family member/friend', while 19\% (India) and 33\% (Germany) named the 'treating physician' as the supporting person. Eighty-four per cent of the Indian and $86 \%$ of the German patients thought that their doctor had informed them honestly about the therapy they have received. Furthermore, the majority of both study populations (79\% India and $90 \%$ Germany) believed that a talk with the treating doctor is the most effective and patient-friendly information source about the illness and therapy.

Seventy-two per cent of the Indian patients compared to $39 \%$ of German patients would ask for a second opinion from another specialist/doctor, while $17 \%$ (India) and $48 \%$ (Germany) would ask their family doctor to find out that the therapy they are receiving is the right one.

Compared to $20 \%$ of the German patients not a single Indian patient would seek information from the Internet regarding this aspect, while $47 \%$ of the Indian patients and $65 \%$ of the German patients wished that there should be an independent source where they could inform themselves whether they are receiving the optimal therapy or not.

To be kept informed about the results and the next steps to be followed in their therapy $49 \%$ of the Indian patients wished for regular letters and $40 \%$ (51\% Germany) wished for a patient's diary compared. Not a single Indian patient reported about contact with a self-help group during the survey compared to $18 \%$ of the German patients.

\section{Psychological aspects}

According to $24 \%$ of the Indian patients, nutrition was the cause of their illness, while $12 \%$ thought the environmental factors and $10 \%$ thought that stress in the family were the main cause. Compared to that $28 \%$ of the German patients said that environmental factors were the main cause of the illness and further $26 \%$ of thought stress at work and further $24 \%$ stress in the family to be the cause of their illness.

Fear of the future was the most difficult aspect of their illness to handle by both study populations ( $43 \%$ India / 55\% Germany).

When asked what they were doing to influence the course of their illness favorably, $85 \%$ of Indian patients stated to follow strictly the instructions of their doctor and $13 \%$ stated to maintain a healthy diet. Out of the German population, $69 \%$ stated to fight against the disease and not let themselves go, while $65 \%$ tried to influence the course of their illness favorably with positive thoughts.

\section{Discussion}

The aim of the present study was to identify needs and expectation of patients suffering from ovarian cancer in Germany as an example of a developed country and in India representing a developing country. 
Regarding the stage upon first diagnosis, the study observed that Indian patients were diagnosed at and significantly more advanced stadium in comparison to the German patients and especially wished for a shorter duration of treatment, which fits to the trends observed in India in previous data $[11,12]$. This observed difference could be explained by studies conducted in India13 and Pakistan [14], where there was a statistically significant relationship between the use of TCAM (Traditional, Complementary and Alternative Medicine) and the delay in seeking help from conventional medicine. The use of alternative or traditional medicine is wide spread in case of Indian patients $[15,16]$. The inaccessibility (long distance, high costs) of standard medical care has the biggest influence in developing countries in using unconventional medicine [17]. In developing countries ignorance, lower socioeconomic status and inadequate access to mainstream medical facilities are major factors that play an important role for patients opting for alternative therapies that are replacements for mainstream treatment. Whereas in developed countries a significant proportion of cancer patients try complementary therapies as adjuncts to mainstream care for management of symptoms and to improve quality of life18. It could be concluded that in India as well as in Germany the treating physicians should offer and explain about other therapy options available in addition to the present treatment.

Although the optimal treatment of ovarian cancer begins with cytoreductive surgery followed by combination chemotherapy $[6,19,20]$, in the present study we observed that $32 \%$ of the Indian patients did not receive an operation. The surgical treatment of ovarian cancer is a large intervention with a long stay in hospital, which would be very expensive in India. The hospitals with facilities to treat cancer patients are more centralized and located only in bigger cities. From the discussion with Indian doctors, patients and their relatives regarding the lack of surgical treatment, it was revealed that poverty and long distance of the patient's home from appropriate hospital facilities is the main reason.

Regarding chemotherapy the result of the current study correlate with previous in India conducted studies. The study of Basu et al. [6] showed that due to the prohibitively high cost of the medicines, most of the patients couldn't afford the treatment of first choice (carboplatin/paclitaxel) and settle for the cisplatin/cyclophosphamide combination. Furthermore, due to the lacking number of beds in hospitals, the cycles of chemotherapy cannot be maintained properly for most of the patients and many patients don't finish chemotherapy as they find it difficult to visit the hospital regularly. In the present study $49 \%$ of the Indian patients received cisplatin and only $12 \%$ carboplatin.

From the result of the study, it could be assumed that German patients had better access to supportive therapy and medical care compared to Indian patients. Surprisingly less Indian patients (34\%) experienced fatigue/exhaustion as a side effect in compared to German patients $(58 \%)$. In the study conducted by Oskay-Özelik et al. [21] $62 \%$ of patients described physical weakness as the most frequent side effect. Regarding low percentage of 'fatigue/ exhaustion' in case of the Indian patients in spite of less use of supportive therapy it may be assumed that they considered 'fatigue/ exhaustion' as the natural process of the disease and did not think to mention it as a disturbing side effects.
Pain was one of the important side effects of both the patient collectives, which correlates with the results of the observation made by Pal et al. [22] and Oskay-Özelik et al. [21]. Thirthy-eight of the Indian patients wished a better and optimized management of pain and $27 \%$ of the Indian patients hoped for a less painful course of disease. A conclusion of this observation should be an improved pain management by the treating physician and more professional training regarding the proper assessment of pain and use of pain medications.

In spite of the vast difference in the therapy management of ovarian cancer between the two study populations, there was no significant difference observed regarding many aspects of patient's experiences such as the completeness and understanding of previous therapeutic consultations, competence of doctors, participation in therapy decisions and involvement of their relatives in the course of the treatment. Similar results were also observed in the perception of therapy success, side effects of the therapy, pain, nausea and the level of exhaustion. The treating physician was named the most effective and patient friendly information source for the both patient collectives (90\% of the German and $79 \%$ of the Indian patients), which correlates to the observations made by Öskay-Özelik et al. [21] und Jenkins et al. [23].

In contrast to the previous studies conducted by Kishore et al. [24] and Ray et al. [25], in which the cancer patients in India were discriminated and to some extend isolated from family/society, the current study showed a large involvement of family members in the course of the disease.

\section{Conclusion}

The results of the present study show a large discrepancy between the Indian and German patients regarding diagnosis, therapy and after care management, while the satisfaction of patients with the therapy management and the treating physician does not differ between the two study populations despite different health care system.

\section{References}

1. Ferlay J. Estimates of cancer incidence and mortality in Europe in 2008. Eur J Cancer. 2009; 46: 765-781.

2. Ferlay J, Steliarova-foucher E, Lortet-tieulent J, et al. Cancer incidence and mortality patterns in Europe: Estimates for 40 countries in 2012. Eur J Cancer. 2013; 49: 1374-1403.

3. Agarwal G, Surg PDCE, Pradeep PV, et al. Spectrum of Breast Cancer in Asian Women. 2007: 1031-1040.

4. Murray SA, Grant E, Grant A, Kendall M. Primary care. 2003.

5. Ferlay J, Soerjomataram I, Dikshit R, et al. Cancer incidence and mortality worldwide: Sources, methods and major patterns in GLOBOCAN 2012. 2015; 386.

6. Basu P, Mandal S, Ray K, Biswas J. Study of 'patterns of care' of ovarian cancer patients in a specialized cancer institute in Kolkata, eastern India. 2009; 46: 28-33.

7. Council I. National Cancer Registry.

8. Murthy NS, Shalini S, Suman G, Pruthvish S, Mathew A. Changing Trends in Incidence of Ovarian Cancer-the Indian Scenario. 2009; 10: 1025-1030.

9. Surbone A. Cultural aspects of communication in cancer care. Support Care Cancer. 2008; 16: 235-240.

10. Oskay-Özcelik G, Alavi S, Richter R, et al. Expression III: patients expectations and preferences regarding physician-patient relationship and 
clinical management-results of the international NOGGO/ENGOT-ov4-GCIG study in 1830 ovarian cancer patients from European countries. Original articl. 2018; 29: 910-916.

11. Dinshaw KA, Rao DN, Ganesh B. Tata Memorial Hospital Cancer Registry Annual Report, Mumbai, India. 1999.

12. Government of India. Annual Report 2005-2006. New Delhi: Ministry of Health \& Family Welfare. 2006

13. Broom A, Nayar K, Tovey P, Shirali R, Thakur R, Seth T, et al. Indian Cance Patients' use of Traditional, Complementary and Alternative Medicine (TCAM) and delays in presentation to Hospital. Oman Med J. 2009; 24: 99-102.

14. Malik IA, Khan NA, Khan W. Use of unconventional methods of therapy by cancer patients in Pakistan. Eur J Epidemiol. 2000; 16: 155-160.

15. Chatterjee A, Ganguly S, Pal SK, Chatterjee A, Mukhopadhyay G, Bhakta RS. Attitudes of patients to alternative medicine for cancer treatment. Asian Pacific Journal of Cancer Prevention. 2005; 6: 125-129.

16. Pal SK. Use of alternative cancer medicines in India. Lancet Oncol. 2002 3: 394-395.

17. Sehouli J, Stengel D, David M, et al. Use of Unconventional Cance Treatments (UCT) among patients with gynaecologic malignancies in Angola. Journal of Clinical Research and Clinical Oncology. 2002; 128: 595.

18. Shukla Y, Pal SK. Complementary and alternative cancer therapies: past present and the future scenario. Asian Pacific Journal of Cancer Prevention. 2004; 5: 3-14.
19. Aletti GA, Gallenberg MM, Cliby WA, Jatoi A, Hartmann LC. Current Management Strategies for Ovarian Cancer. Mayo Clinic Proceedings. 2007; 82: $751-770$

20. Chobanian N, Dietrich CS. Ovarian cancer. Surg Clin North Am. 2008; 88: 285-299.

21. Oskay-Özcelik G, Lehmacher W, Könsgen D, et al. Breast cancer patients' expectations in respect of the physician-patient relationship and treatment management results of a survey of 617 patients. Annals of oncology. 2007; 18: $479-484$.

22. Pal SK and Mittal B. Improving cancer care in India: prospects and challenges Asian Pacific J Cancer Prevention. 2004; 5: 224-226.

23. Jenkins $V$, Fallowfield L, Saul J. Information needs of patients with cancer: results from a large study in UK cancer centres. British Journal of Cancer. 2001; 84: 48-51.

24. Kishore J, Ahmad I, Kaur R, Mohanta PK. Beliefs and Perceptions about Cancers among Patients Attending Radiotherapy OPD in Delhi, India. Asian Pacific J Cancer Prev. 2008; 9: 155-158.

25. Ray K, Mandal S. Knowledge about cancer in West Bengal-a pilot survey. Asian Pac J Cancer Prev. 2004; 5: 205-212. 